\author{
Ryszard W. Kluszczyński \\ https://orcid.org/0000-0003-1073-9805 \\ University of Łódź \\ rwk@uni.lodz.pl
}

\title{
VISUAL REVOLUTIONS: FROM ELECTRONIC TO LIVING IMAGERY
}

\begin{abstract}
I analyse five forms of images: electronic, digital, interactive, networked and living, all of which challenge traditional descriptions and expectations. I analyse them from the technicalontological, phenomenological and cultural perspective to demonstrate different ways in which they discuss and deconstruct the notion of an image. Finally, I try to propose a new context for understanding the discussed forms of new imagery, i.e. the context of post-imagery.
\end{abstract}

Keywords: image, technical image, image-revolution, image-catastrophe, image-performance, image-rendition, transgression.

\section{The cybercultural turn}

The development and spread of new computer and communication technologies in every field of social practice has given rise to profound and ongoing transformations in contemporary culture over the last few decades, leading to changes which have resulted in culture assuming a cybercultural form. All the major "turns" heralded in the humanities and social sciences in recent years, including those related to the visual, experience, memory, performativity and, finally, digitality, should be viewed - though this is rarely said - in the light of how closely they are tied to new media and the rise of cyberculture. Moreover, a number of tendencies have played a major role in this process of cultural change and, as such, they need to be carefully analysed by those working in cultural studies. They include virtualisation, a product of the dynamic development 
and spread of electronic imagery, and the formation of digital environments, both in the form of virtual worlds such as Second Life and earlier DDS (De Digitale $\mathrm{Stad}^{1}$ ), as well as Internet portals, telematicity and media experiences; the role played by digital and, in particular, online databases in the process of externalising memory; the performatisation of social behaviours arising from the ascendant growth of interactive communicative practices; and the sense of participation and community that have emerged as a result of the spread of social media and the culture of Web 2.0 and 3.0. All of these factors together comprise a complex, extended process of change, which can be described as a "cybercultural turn" from today's perspective, in relation to which earlier turns seem to have served as preparatory stages or component parts. However, since the social processes generated by new media are ongoing and ever new structures are being created in cyberculture, it is on these new media that cultural studies should primarily focus. Researchers in cultural studies in Britain first stated years ago that their discipline needed to make work on the media and the consequences of their functioning its highest priority. Today, in the light of the changing shape of new media, which now permeate the fabric of society more deeply and engage participants in communicative practices more powerfully than ever - this thesis is even more compelling. Out of all the processes that fill the space of cyberculture, in the discussion that follows I address only those within the realm of the visual, focusing on the production and functioning of images, their history as media, and the transformations they have undergone. In this discourse, particular attention is paid to visual discourses in the arts.

\section{Cybercultural art}

Art that uses digital technologies as tools, environments for creative work and as media for expression, offers particularly vivid examples of the processes involved in building the world of cyberculture. The artistic structures, creative models, and strategies for organizing experience that are growing out of new media function as indicators of art's perspectives for development and help shape new cultural paradigms. Postmodern creative gestures, such as repetition, processing or remixing are now being iterated in new conceptual contexts, among which transgression and hybridity seem to play particularly important roles. The new artistic order defined by them naturally involves, above all, the visual and audiovisual spheres, assigning new formats to images, perspectives and functions, although also emerging from this sphere are numerous multiand hyper-media works involving multi-sensory experiences, which are of extre-

1 See M. J. Van Lieshout, Configuring the digital city of Amsterdam, "New Media \& Society" 2001, Vol 3 (1), pp. 27-55. 
me importance to the artistic and cultural orders that are to come. New, hybrid forms of imagery, transmedial structures such as the sound-image or wordimage, are taking shape. The image is also developing new functions, becoming a map of a space, then merging with it, transforming into an element in a threedimensional environment and next - in augmented reality. These processes are also leading to changes in the ways we relate to images, when facing an image is being superseded by being-with an image or a being-in an image. The image is thus ceasing to perform a representative function and is becoming a subject or environment, or even an interface for interactive experience instead. Narrativisation of the image, reflecting individuals' needs to create histories, is also occurring - narrativisation that is leading to new forms of visual discursivity. All of these processes present methodological challenges and create new areas for research, such as the ethnography of virtuality, leading ultimately not only to reflection upon these new artistic orders, but also consideration of the cultural consequences of ongoing change in new media. Reflections upon these issues, on cyberculture and on the artistic practices that help articulate - and explain - them comprise a single, hybrid, processual whole.

\section{Visual Revolutions}

The process that gave birth to the present state of images began almost two hundred years ago. Successive inventions and their use in the creation of images and in visual artistic practices have gradually transformed images, moving them in the direction of their present, most likely temporary, state. An analysis of these phenomena allows us to discern within them five critical events, five visual revolutions, the consequences of which make up the current paradigm of the visual sphere: the technological, electronic, digital, interactive and networking revolution. As, in the context of some of these, I will focus on how the transformation of the image essentially leads to the need to question it, in my further analysis of these "turns", in reference to images I will use both the expressions 'quasi-image' and 'image' supplemented by the term designating a given turn, for example, electronic 'quasi-image' or 'digital image', regardless of whether research conducted here leads to questioning the visual status of the analysed phenomenon or not.

\section{Technological revolution}

All of the above-cited processes that have led to profound transformations in visual culture and to fundamental changes in the status of the image, began in the first half of the nineteenth century with Louis Daguerre's and Nicéphore Niépce's invention of a prototype photographic camera. This invention and the 
medium that emerged from it, which later found its continuation in another medium - film, initiated the first in a series of revolutionary transformations that affected the realm of visuality and subsequently, not surprisingly, the visual arts as well. Along with photography, a number of automatic processes were introduced into various cultural practices. Technology supplanted humans, automating elements of the creative process in the field of imaging. These processes did not merely - as in the case of graphic art - support the process by which an artistic vision was transformed into an artefact or provide means for duplicating and reproducing images, but rather merged the creation of the vision and the creation of the material image-artefact into a single technologically-controlled process. Humankind, in its creative use of the photographic or film medium, controlled the machine, but the machine - which did not dare yet, that is, not in the early years of the existence of both technologies, to be called 'creative' - controlled the process of creating images.

The mechanisation of the creative process and the automation of the activity of creating an image, initially led the art establishment to reject the artistic aspirations of photography and film. The history of these two media is for this reason longer than the history of their artistic use and longer than the history of photographic and film art. In the early years of both the media, they were appreciated for a variety of different possibilities and potential functions, for example, as tools for producing entertainment and as scientific instruments. Adding artistic potential to these possibilities required not so much further technological progress in the domain of media, as a transformation of the art world and changes within its institutionally shaped definitions, concepts, notions and paradigms.

Successive revolutions in imaging technologies and practices that followed the first revolution did not forsake the environment it introduced. What they produced built upon the foundation provided by technological media, combining them in multi-dimensional, inter-, multi- and hypermedia structures, thereby fostering advancements in the process of hybridisation that both media and media art are undergoing.

\section{Electronic revolution}

The second revolution reached a critical point one hundred years after the first one, although preparations for it had begun much earlier and continued during the last quarter of the nineteenth century, when the idea was conceived of using scanning as a means for transmitting technological images and Paul Nipkov patented (in 1884) the first electromechanical television system. However, it was not until 1927 that Philo Farnsworth created the first electronic mechanism for scanning images. Four years later, Manfred von Ardenne in- 
troduced the cathode-ray tube as the technical basis for both television broadcasting and the projection/presentation of television images. At this point, television and the television image achieved their final form, the one to which the present discussion refers (although television later underwent significant changes and numerous improvements, it retained the basic principles and operated according to the logic established at this time). In the late 1920s, electronic television entered public space, as broadcasts became increasingly regular (in Germany, UK and the USA).

During television's long period of incubation, technological media - photography and film - were finally accepted by the art world, although for a very long time they were ascribed an inferior position. ${ }^{2}$ Television eventually also acquired the status of an artistic medium, becoming the basis for video art some thirty years later, when Nam June Paik in March 1963 and Wolf Vostell later that year, held their first exhibitions in which both (in different ways) used television sets. ${ }^{3} \mathrm{~A}$ few years later, in a famous exhibition ("TV as a Creative Medium") featuring the work of more than a dozen artists that opened in May 1969 in the Howard Wise Gallery in New York, video art was finally and explicitly recognised and presented as a creative use of the electronic medium of television.

Television is primarily a telematic medium which is used to transmit realtime remote images and sounds (I will modify this claim later in my interpretation of the status of digital images), and establish coexistential ties between the sites involved in the transmission in the viewer's experience. However, what interests me in these considerations is not so much the transmission itself and the properties it endows television with, as the electronic images that appear on the television screen, which are fundamental to it. What is both their basic characteristic and the most important problem they introduce into a discussion of visuality, is the question of their existence or rather non-existence.

Materiality creates a link between photographic images, film and all previous types of images. Irrespective of the means by which we access them during the viewing experience (as object-artefact or projection), we are dealing with the presence of a material form (structural and structural/materialist film showed; moreover, the materiality of film can also be seen in its projection, thus becoming an aspect of the screen effect). This also means that photogra-

2 Video art was next to inherit the status of a discriminated medium, following its ennoblement in the art world at the end of the twentieth century; cf. U. Lehmann, Notes on the "Museumization" of Video Art, [in:] Videonale 6 Catalogue, ed. R. Altstatt, Bonn 1994.

3 It is worth recalling the Luminoscope, invented by Nicolas Schöffer, which the artist used in 1961, creating and presenting the first television art form Variations Luminodynamiques 1. The history of video art thus begins then - in 1961 - and not in 1963. 
phic images and film are characterised by their permanence and persistence in time (changes that appear over time are not treated as new properties of the image, but as the result of a flaw or damage). This is different, however, in the case of electronic images. In the first stage of development of television technology, they appeared on the screen as a result of the collision of electrons emitted by a cathode with the luminophore-coated surface of a cathode-ray tube (CRT). A stream of electrons deflected vertically and horizontally on the CRT screen, and created glowing images. In fact, these are not actually images, but rather events, with a status more akin to light performances. They do not create a permanent artefact, but vanish along with the moment of their presentation, thereby freeing up space for successive performances of images. ${ }^{4}$ As such, it is difficult to agree with the thesis of Jean-Paul Fargier who ascribes a link "with all the realistic ideology of Bazin" 5 to electronic images - a bond which, in his opinion, is broken only by digital images. The effect of immediacy (i.e. telematicity) which Fargier explains by means of this statement is not, however, a feature of electronic images themselves, but of a television broadcast. A similar mistake in confusing electronic and digital images is made by Alain Renaud, when he assigns the feature of eventfulness only to digital images which occur in his conception as "fleeting illusions". ${ }^{6}$ It is actually electronic and not digital images that are image-events or "fleeting illusions". The former are the result of a collision of electrons with the surface of the screen, so it is these images that deserve to be called technological catastrophes. I would rather ascribe the status of image-renderings to digital images. I would also say that they should be assigned some sort of permanence, rather than ephemerality. More is written about it in the next section, since this topic requires a more thorough analysis.

The second revolutionary upheaval in the field of imaging thus deprives images of existence. They cease to exist as material artefacts, becoming events or light performances instead. Electronic quasi-images, along with their existence, also lose the ability to represent reality; any form of representation that might possibly arise in this context, legitimised by telematicity, is a function of the television broadcast. Telematic representation realised by means of real-time transmission, however, assumes the properties of a presentation, thus erasing the boundary between iconicity and indexicality. Instead of a visual representation of an absent reality, we are dealing with the telepresence of transmitted

4 Today's television technology calls electronic images into existence in a different way, but eventfulness still remains their primary attribute.

5 J. P. Fargier, L'Ange du digital. Mallarmé a-t-il inventé la vidéo? "Cahiers du Cinéma” 1986, Numéro Spécial Oů va la vidéo, Hors série, p. 97.

6 A. Renaud, L'image numérique ou la catastrophe technologique des images, [in:] 3e Semaine Internationale de Vidéo, Saint-Gervais Genève, ed. André Iten, Genève 1989, p. 25. 
worlds situated between representation and presentation here. Television thus broadcasts places and not images; the latter are created in real time on the television screen.

The position of video technology (and video art), understood as a medium for creating electronic recordings, appears somewhat different in this context. It seemingly operates by means of electronic images which are produced and stored on a medium - videotape. In fact, however, we are merely dealing with an electrical signal and a magnetic field with mutually correlating parameters, while the creation/recording of images actually turns out to be the result of magnetization of the surface of ferromagnetic tape. The image itself is thus replaced by an electrical signal and a magnetic field. Quasi-electronic images, in this case as well, occur only on the screen of a video monitor, but this time the source is not a television broadcast signal, but a device capable of translating a magnetic recording into an electrical signal which later becomes a source for the emission of electrons. However, in contrast to electronic television images, video images possess a kind of permanence, due to their roots in electromagnetic procedures and their physical deposition on tape. They can be repeatedly displayed on the basis of the same recording, thus achieving the possibility of transcending and overcoming its non-existence. Such permanence, however, is secondary, in fact. It is first the permanence of the electromagnetic recording and only later of its visualisation. To be more precise, this kind of permanence is not actually the permanence of the image, but of the possibility of its presentation. Thus, in the context of this discussion, the permanence of the video image itself merely lies in its readiness to appear.

\section{Digital revolution}

The first digital image, produced by a scanner, was created in 1957 by Russell Kirsch. This started the third revolution in the realm of images. Of course, there was a preparatory period preceding the emergence of digital images, primarily associated with the development of computer technology. In subsequent years, advances in computer technology resulted in the dynamic proliferation of digital imagery which spread to many spheres of social practice and offered numerous varieties of images.

Some of the features found in my earlier analysis of electronic images and problems related to them return here in my interpretation of digital images above all, their non-existence. Digital images are also characterised by a kind of eventfulness and withdrawal from the sphere of material artefacts. In this case, however, as I mentioned earlier, the eventfulness of quasi-images is not associated with them having an ephemeral status. Irrespective of the visualisation technology used, the foundations of digital imagery are permanent. Thus, while 
electronic images fully deserve to be called 'events', I would prefer to retain the term 'rendition' in relation to digital images, as I mentioned earlier. The semantic proximity of these two categories, however, also points to the similarities between the two forms of quasi-imagery discussed here, thus encouraging us to define the differences between them more precisely. Thus, with regard to television pictures, the difference between an electronic event and a digital rendering is based on the singularity of the event compared to the potential for multiple identical renderings. However, in the case of video images recorded on tape, we are confronted with the opposition between the potential for multiple repetitions of the same electronic event and the possibility of a large number of differing renderings of a digital image. The dissimilarity between the two comes from the possibility of modifying a digital image which still retains its identity as a multiplicity of potential forms (I return to this issue again when analysing the networking revolution), while the ability to reproduce a magnetic recording always leads to the same visual event and change is treated as a defect. This distinction is blurred in the context of video synthesisers which, even in an analogue version, create the potential for performative diversity, which inclines me to repeat once again the thesis offered earlier about the affinities between electronic and digital images.

The potential for different renderings of the same digital image emerges from the characteristics of digital media. Lev Manovich, for example, proposes distinguishing five basic characteristics they possess: numerical representation, modularity, automation, variability and cultural transcoding. ${ }^{7}$ Just the first of these properties, fundamental to the emergence of digital imagery, reveals a wide spectrum of possible renderings, indicating that every new media object is a number derived from algorithmic processing, which then leads to the claim that new media are programmable (with respect to images, this means, for instance, the ability to modify contrast, colour saturation and temperature, or the size and aspect ratio). Additional features include modularity and variability which complement the perspective under discussion, according to which the digital image should not be seen as a single entity, but as a multiplicity of possible renderings - a network of potential images.

The problems associated with representation that I noted earlier with regard to the electronic image appear here as well, but this time they have a completely different source. Among their many attributes, digital media possess the feature of generativity. When it reveals itself as a dominant property in a given situation, the rendered digital image ceases to refer to a reality outside of itself, offering only itself instead, which means the replacement of representation

7 L. Manovich, The Language of New Media, MIT Press 2001. 
with presentation. ${ }^{8}$ The image takes on a form defined by Jean Baudrillard as a simulacrum, ${ }^{9}$ or, in the words of Woody Vasulka, it becomes a digital object. ${ }^{10}$

The digital revolution thus continues the process of dematerialising the image begun by its predecessor. Its non-existence here is formatted algorithmically; the image, given permanence in a numerical form, remains in a state of infinite willingness to assume diverse renderings on many different devices built on a meta-medial computer foundation. The diversity of available devices corresponds to the multiformity of digital images: 2D, 3D, layered tomographic images (CAT) and virtual reality environments are only a few of the numerous possible examples.

\section{Interactive revolution}

Interactivity in art has many faces. It can be seen in the interactivity of the medium or in the interactivity of the work. Among interactive media, the dominant position is currently held by digital media. On the other hand, however, cybernetic and robotic media should not be disregarded, as they once surpassed or rivalled digital media in terms of their development. The same applies to biotechnology and neuroengineering which are now bringing about profound changes in digital media, as well as hybridising them. Among interactive works, we find an even greater variety of manifestations of interactivity, with artists such as Bernie Lubell or Theo Jansen, demonstrating in their works that interactive artworks can be created using a minimum of technology.

The variety of forms (of digital imagery) mentioned in the previous section is also repeated in the context of interactive images. They assume many different shapes. They can, for example, occur on a flat computer screen, but they may also appear in a virtual environment managed interactively by means of VR instrumentation.

In addressing questions related to screen images, the classification of screens proposed by Lev Manovich is also worth recalling. ${ }^{11} \mathrm{He}$ identified four types of screens: classic, dynamic, real-time and interactive. In the context of our

8 See also I. Hoelzl and R. Marie, Softimage. Towards a New Theory of the Digital Image, Intellect, Bristol 2015.

9 J. Baudrillard, Simulacra and Simulations, [in:] J. Baudrillard, Selected Writings, ed. Mark Poster, Stanford University Press 1988, pp. 166-184.

10 M. Sturken, Exploring the Phenomenology of the Electronic Image, [in:] Steina e Woody Vasul$\mathrm{ka}$. Video, media e nuove immagini nell'arte contemporanea, ed. M.M. Gazzano, Fahrenheit 451, Roma 1995, pp. 33-34.

11 See L. Manovich, Towards an Archaeology of the Computer Screen, in Cinema Futures: Cain, Abel or Cable? The Screen Arts in the Digital Age, ed. Thomas Elsaesser and Kay Hoffmann, Amsterdam University Press 1998, pp. 27-44. 
discussion, a classic screen is associated with photography. A dynamic screen, in contrast, is associated by Manovich with film, television and video, a realtime screen with radar, and an interactive screen with the computer. My earlier analysis of the electronic image leads me to modify the typology proposed by the author of The Language of New Media and to exclude both television and, to a lesser extent, video from the dynamic screen. The images created by these two media come into being on the screen of a monitor in real time. I would thus categorise television as an example of the real-time screen. However, the status of the video image is ambivalent; its readiness to re-appear on the screen repeatedly by means of an electromagnetic recording leads us to perceive it as a hybrid form combining characteristics found in the dynamic and real-time screen. ${ }^{12}$

Interactive virtual environments eschew traditional imagery in yet another way. They are no longer situated and available solely on a screen placed before an addressee-user, outside of his/her material reality; they surround them on all sides instead, immersing them in a simulated world and letting them centrically, and therefore also physically, experience a causative, telematic presence in virtual reality.

Interactive images in all their forms widen the gap between the realm of classical paintings and contemporary forms of visualisation, a gap that emerged and evolved with the advent of electronic images. Contemporary images and quasi-images do not only appear in real time as events or renderings, questioning their own existence as entities persisting in time, not only failing to fulfil the requirements of representation, not depicting anything outside of themselves, but also succumbing to manipulation from addressee-users, becoming a component of the very reality in which they dwell. These images are transformed into tools for action, interfaces creating the possibility for a wide range of forms of communication and interaction with hardware and software. The perceived objectivity of digital images is transformed into the instrumentality of interactive images here.

In the world of images today, we are often faced with complex, hybrid visual systems, within which the various manifestations of imagery cited above intertwine. Some types of images perform the function of generators, calling into existence a variety of visual forms and processes, while others serve as meta-images, managing the selection and appearance of images from other planes of the visual realm, and still others play the role of instruments/interfa-

12 Manovich seems not quite sure where to place television in his typology. First, he unambiguously assigns it to a dynamic screen, stating that it includes the cinema, TV and video, but then elsewhere in the same text, writing about radar, he says that television is based on the same principle, assigning it this way to a real-time screen. 
ces for manipulating these images. Virtual objects forming autonomous virtual environments (virtual reality), through processes similar to hybridisation, link themselves to material objects, taking the form of expanded or enhanced reality (augmented reality). In all these contexts, interactive images, regardless of the form they possess and immediate function they perform, transform the visual realm of eventfulness shaped by electronic and digital images. In lieu of contemplated images-events, interactive image-tasks appear and in lieu of aesthetic distance - participatory responsibility. ${ }^{13}$

Interactive artistic forms of imaging, rooted in cybernetic and electronic technologies, appeared in the 1950s in the work of Nicolas Schöffer. They were further developed in the decades that followed by numerous artists who turned to digital technologies: Myron W. Krueger, Jeffrey Shaw, Lynn Hershman, Luc Courchesne, Grahame Weinbren, Char Davies, and Jill Scott, to name but a few of the pioneers of (audio)visual interactive art, who quickly dominated this field of artistic practice to such an extent that many researchers of new media art began to identify it with interactive art.

\section{Networking revolution}

The particular visual revolutions characterised here can be viewed not only as separate phenomena, but also as successive stages ${ }^{14}$ in a complex process leading to a multilateral transformation of the world of images. Technological images evolved into electronic ones that then turned into digital ones which then assumed the attributes of interactivity and, ultimately, were placed on networks. ${ }^{15}$ The successive forms of imagery possessed the properties found in those from the previous revolutions. The automatisation of images evolved into autonomisation characteristic of the technological revolution and was supplemented by the eventfulness of non-existent electronic images, and then by the rendering of digital images. Interactivity maintained the numerical permanence of digital images, inscribing them into an unending process of transformation undertaken by their users. All of these properties together formed the paradigm of new iconography that we refer to today in the process of creating,

13 Cf. I. Hinterwaldner, The Systemic Image. A New Theory of Interactive Real-Time Simulations, MIT 2017.

14 This succession of events should rather be understood as a consequence in the logical and not chronological sense. The agendas of these revolutions are in fact complex and do not lend themselves to linear presentation.

15 Of course, next to images hybridized in this way in the iconosphere, there are also simpler images representing various stages of the transformation and various revolutionary upheavals. 
interpreting and using images. What did the networking revolution offer to this paradigm?

Images were linked in networks. However, they also became networks. In writing here about networks, I am not limiting the use of this category to the web only. This is not just because of the fact that modern networks are highly diverse and increasingly converged, including Internet, Ethernet, telephone and geolocation networks, and operating on both wired and wireless infrastructures. Within these, additional networks are created on different levels, such as Twitter or Facebook. Yet, it is also because, as has already been mentioned, the images themselves have become networks. Digital images, in accordance with their nature as media, are modular networks. For the same media-related reason, each digital image is a network of its potential variations. Furthermore, interactive images are networks of virtual or real variants formed in interactions between users. Each of these varieties of networks leads us into the world of image-specific properties, also making them advanced multi- and hyper-media structures. The transgressive character of modern computer and communication technologies imbues images with a similar transgressive nature. Transmedial nomadity becomes one of their basic properties.

On the Internet as well, images not only become linked online, thus building a specific kind of complex sets - (audio)visual clusters. Individual images and sequences forming a single moving image can also become complex units - networks, not just because of the previously-mentioned properties of digital media, but also as a result of coordinated cooperative action within a network consisting of multiple websites. Olia Lialina's work Summer (2013) serves as an excellent example of such a solution. On the browser screen, we see an animated looped image of the artist swinging on a swing. However, each of the images that comprise this animation (GIF) is being played on a different website; the browser is redirected from one server to the next and the speed and smoothness of the animation depend on the infrastructure of the Internet connection used by the viewer. The work is fully rooted in the Internet, even an emanation of it. As the artist points out, it is impossible to see Summer offline. ${ }^{16}$

Networking of the image creates a fragmentary, but simultaneously new overarching order - the network - as the horizon defining the experience of images. Each image is both a fragment and a network whole. In the world of images, there is no longer anything apart from the fragment and the network. 


\section{The post-revolutionary landscape: in a world of postimages}

All the types of images I have analysed here, all of which entered our lives after photographic images and film, and therefore after the technological revolution, and which I defined earlier alternately as images and quasi-images, will from now on be called postimages in the paper. I suggest such a label because, on the one hand, they share a common history with images. Moreover, from the perspective of their viewers and users who do not interpret their status theoretically, they are still experienced merely as images to a greater or lesser degree. On the other hand, however, in comparison with classical images, they have a completely different set of characteristics, as well as other means of existence and of manifesting themselves. In his reflections on real-time screens, Manovich even questioned the possibility of images existing there in the traditional sense. He claimed that we call what we see on a real-time screen "images" only out of habit. ${ }^{17}$ Interactive screens, their contents and network images have intensified this process, depriving us of our remaining reasons for referring to them as images. They have developed in this way and broadened the horizons of postimagery.

Mobility and nomadic postimages have moved them into the context of numerous dispositives that accompany us in everyday life, giving the global perspective of new media a local rooting in individuals and communities. It has moved them not only onto the screens of traditional mobile devices, such as smartphones and tablets; they are also inscribed into a postbiological context. Postimages displayed directly onto the retina of the eye, as is the case with Google Glass, integrate and hybridise with human flesh. Therefore, as a factor in cyborgization, they are also becoming an aspect of the transhumanist condition.

In the recent history of imagery, we can notice the emergence of various forms of living images or bioimages which problematise the status, means of existence and characteristics of the image in various ways, creating a challenge for the concept. At this point, it is worth recalling works such as Microvenus (Joe Davis, 1986), DNA Portrait of Sir John Sulten (Marc Quinn, 2001), Relative Velocity Inscription Device (Paul Vanouse, 2002), The Living Screen (Guy BenAry, Tanya Visosevic, 2007). Another example of living postimages is the latest work by the Polish artist Jarosław Czarnecki.

The installation Symbiosity of Creation (2012-) by Jarosław Czarnecki, aka Elvin Flamingo, is constructed from a series of object-incubators designed and built by the artist as a dwelling place for ants. It is their life, with all the forms of activity that comprise it, as well as Czarnecki's actions organising space for

17 See L. Manovich, Towards an Archaeology of the Computer Screen, op. cit. 
their existence and providing the necessary resources, that together define the space of the work. The questions taken up by Symbiosity of Creation are part of the contemporary posthumanist debate which relates to, among other things, the issue of creativity in art: its course, nature, and, above all, its subjects. Czarnecki's installation clearly problematises this issue - the artist turns the ants that he co-operates with while working on the installation into partners in the process of its creation. Agency in the processes that comprise the work, its course, conditions and consequences are here split between the artist and the ants. The processes of creative interaction that occur in Symbiosity of Creation undergo naturalisation; they develop between the artist, the ants and their shared work.

Czarnecki suggests that his work, which belongs to the wider field of biological art (bioart), be seen as a type of a film:

"The concept was to create a kind of a 'film' about which no viewer leaving the 'cinema' could say: "That was a great film, but life goes on. It was just a film." To create a 'film' that lives its own life, participating, interactive and symbiotic with me." 18

Of course, even for Czarnecki himself, Symbiosity of Creation cannot be and is not just a film. The work is multimedia in nature, located at the intersection of film, sculpture and installation, also drawing from the areas of interactive art, bioart, generative art and theatre (or, more broadly, the performing arts). It is profoundly hybrid in nature. However, its association with film justifies certain analytic stances towards this work. If we treat the windows of the incubators as screens, the work becomes a film in the experience of the viewer, something like a form of expanded cinema. We can define this kind of film as living film, while the images that comprise it can either be called "living images" or "bio-images". Their special nature, however, requires us to define them as living or biological postimages.

Postimages are dynamic - they are processes. Therefore, when watched on the screens of incubators, they inspire us to reach for a reconciling cognitive and aesthetic framework in the concept of the film. They are also dimensional (3D) and develop on the basis of the processes occurring within them - this determines the life of the ants. Given this last property, they can also be described as bio-generative. Finally, they are autonomous; they do not perform pre-prepared scripts, but independently execute visual performances. Because of this last property, the windows-screens of the incubators can be included in the domain of real-time screens.

18 J. Czarnecki (Elvin Flamingo), Symbiotyczność tworzenia [Symbiosity of Creation], Akademia Sztuk Pięknych, Gdańsk 2014, p. 3. 
In the case of Symbiosity of Creation, its dynamics and changeability do not result from interactive relations between the system of the work and its audience, nor are they forms shaped by means of other factors that are external to them. They are also not virtual in nature. We are confronted here with live visual events autonomously developing during the course of their action and thus unpredictable. These visual bio-environments, experienced in the context of screens, complete the range of forms of postimage experience considered here.

Their postimagery takes an extreme form, challenging our categories and cognitive habits. They can actually be defined as a material simulacrum in which the representational function has been mixed with that of presentation. As living, organic, material beings, they become postimages, referring to themselves as images and deconstructing their material status for this purpose. ${ }^{19}$

\section{BIBLIOGRAPHY:}

Baudrillard Jean, Simulacra and Simulations, [in:] J. Baudrillard, Selected Writings, ed. Mark Poster, Stanford University Press 1988.

Czarnecki, Jarosław (aka Elvin Flamingo), Symbiotyczność tworzenia [Symbiosity of Creation], Akademia Sztuk Pięknych, Gdańsk 2014.

Fargier, Jean-Paul, L’Ange du digital. Mallarmé a-t-il inventé la vidéo? "Cahiers du Cinéma” 1986, Numéro Spécial O̊̊ va la vidéo, Hors série.

Hinterwaldner, Inge, The Systemic Image. A New Theory of Interactive Real-Time Simulations, MIT 2017.

Hoelzl Ingrid and Rémi Marie, From Softimage to Postimage, "Leonardo” Vol. 50, Issue 1, February 2017.

Hoelzl, Ingrid and Rémi Marie, Softimage. Towards a New Theory of the Digital Image, Intellect, Bristol 2015.

Lehmann, Ulrike, Notes on the "Museumization" of Video Art, [in:] Videonale 6 Catalogue, ed. R. Altstatt, Bonn 1994

Manovich, Lev, The Language of New Media, MIT Press 2001.

19 Cf. I. Hoelzl and R. Marie, From Softimage to Postimage, "Leonardo" Vol. 50, Issue 1, February 2017. 


\section{REWOLUCJE WIZUALNE. OD ELEKTRONICZNEJ DO ŻYJĄCEJ OBRAZOWOŚCI (streszczenie)}

Analizuję w artykule pięć form obrazu - elektroniczny, cyfrowy, interaktywny, usieciowiony i żyjący - wykazując, że wszystkie one stanowią wyzwanie dla tradycyjnego rozumienia obrazu. Analizuję je z perspektywy techniczno-ontologicznej, fenomenologicznej i kulturowej aby pokazać, w jak różny sposób każdy ze wskazanych typów obrazowości kwestionuje i dekonstruuje dotychczasowe pojęcie obrazu. Na zakończenie proponuję nowy kontekst dla rozumienia dyskutowanych tu form obrazowości - kontekst postobrazowości.

Słowa kluczowe: obraz, obraz techniczny, obraz-rewolucja, obraz-katastrofa, obraz-performans, transgresja

Ryszard W. Kluszczyński, PhD, media art scholar, writer and curator.

Professor of media and cultural studies, Chair of Department of New Media and Digital Culture, University of Lodz, Poland. Professor at the Academy of Fine Arts in Lodz. He investigates the issues of new media arts and cyberculture, contemporary art theory and practices, avant-gardes, transdisciplinary cultural transformations, and recent interactions between art, science, technology and politics.

Artistic Director of Art \& Science Meeting Program in the Centre for Contemporary Art in Gdansk (2011-). Curator of numerous exhibitions within the Program. Co-curator of travelling international exhibition United States of Europe (2011-2013). Curator of the Second International Biennale of Contemporary Art "Mediations", Poznan 2010. Chief Curator of Film, Video and Multimedia Arts in the Centre for Contemporary Art - Ujazdowski Castle in Warsaw (1990-2001).

Some of his recent book publications: Beyond Borders: Processed Body - Expanded Brain - Distributed Agency (2019); Augmenting the World. Masaki Fujihata and Hybrid Space-Time Art (2017); Human Traits. Patrick Tresset and the Art of Creative Machines (2016); Guy Ben-Ary: Nervoplastica. Bio-robotic Art and its Cultural Contexts (2015); Ken Feingold: Figures of Speech (2014); Meat, Metal \& Code / Contestable Chimeras: Stelarc (2014); Robotic Art and Culture. Bill Vorn and His Hysterical Machines (2014). 